IZA DP No. 5753

Patients Whose GP Knows Complementary Medicine Tend to Have Lower Costs and Live Longer

Peter Kooreman

Erik W. Baars

May 2011 


\title{
Patients Whose GP Knows Complementary Medicine Tend to Have Lower Costs and Live Longer
}

\author{
Peter Kooreman \\ Tilburg University \\ and IZA
}

Erik W. Baars

University of Applied Sciences Leiden

and Louis Bolk Institute

\author{
Discussion Paper No. 5753 \\ May 2011 \\ IZA \\ P.O. Box 7240 \\ 53072 Bonn \\ Germany \\ Phone: +49-228-3894-0 \\ Fax: +49-228-3894-180 \\ E-mail: iza@iza.org
}

Any opinions expressed here are those of the author(s) and not those of IZA. Research published in this series may include views on policy, but the institute itself takes no institutional policy positions.

The Institute for the Study of Labor (IZA) in Bonn is a local and virtual international research center and a place of communication between science, politics and business. IZA is an independent nonprofit organization supported by Deutsche Post Foundation. The center is associated with the University of Bonn and offers a stimulating research environment through its international network, workshops and conferences, data service, project support, research visits and doctoral program. IZA engages in (i) original and internationally competitive research in all fields of labor economics, (ii) development of policy concepts, and (iii) dissemination of research results and concepts to the interested public.

IZA Discussion Papers often represent preliminary work and are circulated to encourage discussion. Citation of such a paper should account for its provisional character. A revised version may be available directly from the author. 


\section{ABSTRACT \\ Patients Whose GP Knows Complementary Medicine Tend to Have Lower Costs and Live Longer}

Health economists have largely ignored complementary and alternative medicine (CAM) as an area of research, although both clinical experiences and several empirical studies suggest cost-effectiveness of CAM. The objective of this paper is to explore the cost-effectiveness of CAM compared to conventional medicine. A data set from a Dutch health insurer was used containing quarterly information on healthcare costs (care by general practitioner (GP), hospital care, pharmaceutical care, and paramedic care), dates of birth and death, gender and 6-digit postcode of all approximately 150,000 insurees, for the years 2006-2009. Data from 1913 conventional GPs were compared to data from 79 GPs with additional CAM training in acupuncture (25), homeopathy (28) and anthroposophic medicine (26). Patients whose GP has additional CAM training have 0 to 30 percent lower healthcare costs and mortality rates, depending on age groups and type of CAM. The lower costs result from fewer hospital stays and fewer prescription drugs. Since the differences are obtained while controlling for confounders including neighborhood specific fixed effects at a highly detailed level, the lower costs and longer lives are unlikely to be related to differences in socioeconomic status. Possible explanations include selection (e.g. people with a low taste for medical interventions might be more likely to choose CAM) and better practices (e.g. less overtreatment, more focus on preventive and curative health promotion) by GPs with knowledge of complementary medicine. More controlled studies (replication studies, research based on more comprehensive data, cost-effectiveness studies on CAM for specific diagnostic categories) are indicated.

JEL Classification: I11, I12

Keywords: healthcare costs, life expectancy, complementary medicine

Corresponding author:

Peter Kooreman

Department of Economics

Tilburg University

Warandelaan 2

5037 AB Tilburg

The Netherlands

E-mail: p.kooreman@uvt.nl

\footnotetext{
* We thank health insurance company Azivo, in particular Martin Schutte, for providing the data, and Paul de Beer, Katie Carman, Patrick Hullegie, Tiemen Woutersen, as well as three anonymous referees for helpful comments.
} 


\section{Introduction}

Complementary and alternative medicine (CAM) has been largely ignored by health economists as an area of research. That fact is possibly related to the low esteem of CAM in the medical profession.

Defining CAM is difficult, because the field is very broad and constantly changing. According to the National Center for Complementary and Alternative Medicine (NCCAM) CAM is a group of diverse medical and health care systems, practices, and products that are not generally considered part of conventional medicine [1]. The Cochrane Collaboration definition of complementary medicine is that it includes all such practices and ideas which are outside the domain of conventional medicine in several countries and defined by its users as preventing or treating illness, or promoting health and well being. These practices complement mainstream medicine by satisfying a demand not met by conventional practices and diversifying the conceptual framework of medicine [2].

Patients around the globe are increasingly embracing CAM as a contributor to health. A recent study by the US National Institute of Health shows that 4 out of 10 Americans used some form of CAM in 2007. Another study on Switzerland reported that almost $11 \%$ of the population had used one of five CAM streams (anthroposophic medicine, homeopathy, neural therapy, phytotherapy and Traditional Chinese Medicine) in 2002. The CAM doctors in that study treated patients that tended to be younger, female and better educated. These patients also tended to have a favorable attitude towards complementary medicine and to exhibit chronic and more severe forms of disease. The majority of alternative medicine users appear to have chosen CAM mainly because they wish to undergo a certain procedure; additional reasons include desire for more comprehensive treatment, and expectation of fewer side-effects [3]. In a referendum in Switzerland in 2009, two thirds of the voters were in favor of a wider coverage of CAM by public health insurance. In January 2011, based on the positive outcome of a national referendum, the Swiss authorities decided that five main streams of CAM (anthroposophic medicine, homeopathy, neural therapy, phytotherapy and Traditional 
Chinese Medicine) will be covered by the mandatory health insurance for a period of six years (2012-2017) [4].

In many cases, the effectiveness of CAM has not been proven in clinical trials [5]. However, lack of proof of effectiveness is obviously not the same as proof of ineffectiveness. Clearly, the status of a treatment can change from CAM into conventional medicine once scientific evidence on effectiveness becomes available. Two examples of CAM treatments that have become (more) accepted by conventional medicine are St. John's wort and acupuncture for specific indications. St. John's wort, for more than 90 years used in anthroposophic medicine, has become part of the conventional guidelines for the treatment of depression, based on scientific evidence from randomized controlled trials [6]. Hopton and McPherson [7] conclude on the basis of a systematic review of pooled data from meta-analyses that acupuncture is more than a placebo for commonly occurring chronic pain conditions. In addition, in her thesis, van den Berg [8] recently demonstrated positive effects of acupuncture on obstetric health problems (breech presentation). Also Servan-Schreiber [9] presents a series of recent examples of the transition from CAM to conventional medicine in depression treatment. Some of the methods described by Servan-Schreiber have been practiced for centuries, cannot be patented, and are available at low costs. These findings underscore the fact that methods that are considered CAM today could be effective and have a large cost-savings potential.

Anthroposophic medicine, acupuncture and homeopathy are three main streams of CAM. One of the core features of CAM is its orientation on preventative and curative health promotion as an additional approach to a more conventional fighting disease approach. Anthroposophic medicine is an integrative diagnosis and therapy concept, developed from 1921 onwards and practiced today in over 60 countries. It combines mainstream scientific medicine with Rudolf Steiner's anthroposophy. Anthroposophic medicine considers a human being as a whole entity - body, mind, soul and individuality. It aims to stimulate the self-healing forces of the body, restoring the balance of bodily functions and strengthening the immune system, rather than primarily relieve the symptoms of disease. Specific anthroposophic approaches include 
anthroposophic medicinal products, massage therapy, art and music therapy, and speech and movement therapies [10].

Homeopathy is a form of alternative medicine, first proposed by German physician Samuel Hahnemann in 1796, that attempts to treat patients with heavily diluted substances. These substances which cause certain symptoms in healthy individuals are given as the treatment for patients exhibiting similar symptoms. The appropriate homeopathic medicinal product aims to stimulate the body's inherent forces of selfrecovery [11].

Acupuncture is one of the main forms of treatment in Traditional Chinese Medicine (TCM). It involves the use of sharp, thin needles that are inserted in the body at very specific points. This process is believed to adjust and alter the body's energy flow into healthier patterns, and is used to treat a wide variety of illnesses and health conditions [12].

In their review, Herman et al. [13] report that some studies indicate that CAM therapies may be considered cost-effective compared to usual care for various conditions: acupuncture for migraine, manual therapy for neck pain, spa therapy for Parkinson's, selfadministered stress management for cancer patients undergoing chemotherapy, pre- and post-operative oral nutritional supplementation for lower gastrointestinal tract surgery, biofeedback for patients with 'functional' disorders (eg, irritable bowel syndrome), and guided imagery, relaxation therapy, and potassium rich diet for cardiac patients. A systematic review of randomized clinical trials on the use of so-called Natural Health Products shows evidence of cost effectiveness in relation to postoperative surgery but not with respect to the other conditions assessed [14]. Studer and Busato [15] demonstrated that general practitioners who have completed certified additional training in CAM after obtaining their conventional medical degree (GP-CAMs) $(n=257)$ with general practitioners who have not (GPs $)(n=174)$ have equal costs per patient per year, but significantly lower costs per doctor (29\%) per year, although GP-CAMs take more time per patient. A NCCAM study in 2007 demonstrated that CAM costs were $11.2 \%$ of total out-of-pocket expenditures on health care in the USA [16].

GP care varies between European countries in terms of structure, working methods, and responsibilities. In the Netherlands GPs are the central gatekeepers for 
reference to the rest of healthcare, like specialists and paramedics. Dutch general practitioners generally receive a quarterly fixed fee per patient plus a fee-for-service per consultation and per drug prescription. There is no difference between the financial incentives faced by GPs and GP-CAMs. In the Netherlands purchasing basic health insurance is mandatory for all citizens. In addition, citizens are free to purchase supplementary insurance.

Since there is a lack of cost-effectiveness data of CAM in The Netherlands, in this paper, we compare the performance of general practitioners who have completed certified additional training in CAM after obtaining their conventional medical degree (GPCAMs) with general practitioners who have not (GPs). More specifically, we consider GP-CAMs with additional training in anthroposophic medicine, homeopathy, or acupuncture (about 1 percent of GPs for each of these CAM types).

\section{Methods}

\section{Model overview}

We analyze costs at the patient level using linear and loglinear regression analysis. While the linear specification is more common, the loglinear specification can be argued to be more appropriate given that costs are nonnegative and cost distributions typically have long tails. Given the large average differences in health and health care needs across age groups, the cost analysis has been performed separately for the age groups 0-24, 25-49, 50-74, 75+. In all cost regressions, the explanatory variables are: gender, age (linear, within each age category), dummies for each quarter, dummies for anthroposophy, homeopathy, and acupuncture, and 6-digit postal code fixed effects

Effects on mortality rates are analyzed using a Logit model with fixed effects at the 4-digit insuree postcode level. Given the relatively low proportion of deaths (less than 3 percent of insurees died during our sampling period) fixed effects at 6-digit insure level are infeasible. To check for robustness against functional form specification we also analyze mortality using fixed effects Linear Probability Models. 


\section{Dataset on healthcare costs and demographics}

A dataset from health insurer Azivo, active primarily in the city of Hague and its wider vicinity, was used for the analyses. Azivo is a former Ziekenfonds (sick fund) founded in 1895. It merged with health insurer Menzis in 2008, but keeps operating as "Azivo" in the the Hague region. Its share in the market for basic and supplementary health insurance in this region is about one quarter.

The data set contains quarterly information on the healthcare costs of all Azivo insurees for the years 2006 up to 2009. In addition, it contains the date of birth of the insuree, date of death (if applicable), gender, and 6-digit postcode of the insuree's residence. For each insuree-quarter combination, information on the costs of four different types of care are available: care by GP, hospital care, pharmaceutical care, and paramedic care (like physical therapy). The data set does not contain information on the supplementary insurance status of insures; the cost information is the sum of expenses covered by both the basic and (if applicable) supplementary health insurance.

\section{General practitioners}

The data set also contains the names and addresses of the general practitioners who have patients who are insured by Azivo, which allows us to distinguish between conventional GPs and GP-CAMs. We defined a general practitioner as anthroposophic GP-CAM if his or her name appears in the list of general practitioners with additional training in anthroposophic medicine as provided by their professional association [17]. GP-CAMs with homeopathy [18] and GP-CAMs with acupuncture [19] are defined similarly.

\section{Statistical analyses}

Significance of coefficients is tested using $t$-test, with clustering of standard errors at the level of the insuree. Calculations were performed using StataSE 10.0.

\section{Results}

Patient demographics 
The dataset contained information on 151,952 insurees with a mean age of 38.4 $(\mathrm{SD}=22.6) ; 53$ percent is female. These patients live in 21902 different 6-digit postal codes.

\section{General practitioners}

The dataset contained information from 1992 GPs: 1913 conventional GPs and 79 complementary GPs (GP-CAM) (anthroposophy: 26, homeopathy: 28, acupuncture: 25). The number of patients insured with Azivo is highly unevenly distributed across GPs. For example, 5 out the 26 anthroposofic GPs in the data set account for more than 95 percent of the claims by patients with anthroposofic GP. This is because Azivo has a relatively large market share (about one quarter) in the The Hague region and a very low market share in most other regions. The average number of Azivo patients with these 5 anthroposofic GPs is about 570. The corresponding figures for the other GP types are 850 (conventional), 150 (homeopathy) and 360 (acupuncture). The differences can be due to variations in the size of the total practice as well as in variations in Azivo's market share across the four groups of patients.

\section{Healthcare costs}

The costs of patients with a GP-CAM are 7 percent lower compared to conventional GPs, which amounts to 170 Euros per patient annually. However, this difference in raw means of total costs is significant only for anthroposophic GP-CAMs. The lower total costs result from lower hospital and pharmaceutical costs. Patients with a GP-CAM have slightly higher costs for paramedic care, but this difference is small. When the costs are compared by age group, in absolute terms, the differences are particularly large for patients aged 75 and above with an anthroposophic GP-CAM (more than 1000 Euros on an annual basis) (Table 2).

The analyses also demonstrate large demographic differences between patients with a conventional GP versus patients with GP-CAMs (Table 1). GP-CAMs have a larger fraction of female patients than conventional GPs and fewer patients from disadvantaged neighborhoods. Clearly, the costs differences reported in tables 1 and 2 are 
partly due to differences in the demographic composition of the various groups of patients, and therefore difficult to interpret.

After controlling for these demographic differences by means of regression analyses we find that for patients in the age group 25 to 49 with a GP-CAM with acupuncture total costs are 66 euro lower per quarter (Table 3, left panel). Secondly, for patients aged 75 and above with an anthroposophic GP-CAM total costs are about 400 Euros lower per quarter. The magnitude of this difference is large, about one third lower. The separate regressions for the costs components show that these lower costs come from lower hospital and lower pharmaceutical costs. The results for the loglinear specification show a somewhat different pattern. Homeopathic GP-CAMs have about 15 percent lower costs in all three age categories below age 75. The lower costs for patients aged 25-49 who have a GP-CAM with acupuncture are found again for the loglinear specification.

It is important to note that 6-digit postal codes in the Netherlands are highly detailed, representing on 16 households on average. Within such a code households are highly homogeneous in terms of socio-economic status. Given that we have controlled for 6-digit postal codes in the regressions, the results are unlikely to be due to differences in socio-economic status.

\section{Health status}

In the present data set the only information available on health outcomes is mortality in the years 2006 up to and including 2009. For the population of insurees in our data, the mortality rate was approximately 3 percent. After controlling for demographics (including age) and 4-digit postal codes, we find that patients with a GP-CAM have significantly lower mortality rates (Table 4). For all three types of CAM the effect is significant for some specifications, but not for all specifications. The magnitude of the effect again varies between 0 and 30 percent. 


\section{Discussion}

There are four types of explanations for the differences reported in the previous section. First, the differences could be due to selection on unobservables in patients' GP choice. For example, patients who are healthier and more health-conscious, or patients with a strong preference to minimize exposure to medical interventions might be more likely to choose a GP-CAM. In both cases costs will be lower due to lower demand for health care. A standard approach to control for selection on unobservables is to use instrumental variables. A potential instrumental variable (IV) in this case is the distance between a patient's home and the various GPs. However, the distance measures would be perfectly correlated with the 6-digit postal code dummies. As a consequence, this IV would only work if we would control for less detailed neighborhood information, like 4digit postal codes. However, since socio-economic differences within a 4-digit postal code are typically large, this would not be a credible approach for identifying a causal effect of CAM on costs.

Second, the results could be due to undertreatment by GP-CAMs. In the present data set we were only able to analyze mortality and found that patients with a GP-CAM tend to have lower mortality rates. A number of studies have reported that patients seeking anthroposophic or homeopathic care have longer lasting and more severe health problems than patients in conventional care. At the same time, these patients report fewer adverse side effects of treatments and higher patient satisfaction [e.g., 20, 21]. These findings combined with the results in this study provide some indication that undertreatment by GP-CAMs is unlikely. Firmer conclusions require more data on outcomes.

Thirdly, the results could be due to better practices of CAM due to a stronger focus on preventive and curative health promotion and less overtreatment. For example, a GP-CAM might try a low cost CAM treatment first. As mentioned, the primary professional orientation of CAM doctors is to strengthen the self-healing capacity of the body and the self-management of the patient. This approach is associated with prescribing fewer conventional pharmaceuticals, tests, and operations. 
Fourthly, the lower costs could be related to the fact that patients interested in CAM might have higher out-of-pocket expenses since CAM is not included in the basic health insurance package. On the other hand, patients interested in CAM are more likely to buy supplementary insurance that covers CAM. This would imply that the marginal out-of-pocket expenses for these insurees are lower than for insurees with a conventional GP, leading to more consumption of healthcare (recall that the Azivo data contain costs covered by basic health insurance plus costs covered by optional supplementary health insurance). Yet, we find that the costs of patients with a GP-CAM are lower. Clarifying the role of out-of-pocket expenses is an empirical issue that requires additional data.

Several studies that compare the health status of patients treated in CAM and in conventional medicine in primary care settings find that patients treated in CAM practices suffer more often from severe and chronic illnesses (e.g., [20, 21]). This suggests that if we could control for severity and chronicity of illnesses (with additional data), the estimated cost differences might be larger.

Another result of this study is that GP-CAMs have a larger fraction of female patients than conventional GPs and fewer patients from disadvantaged neighborhoods. Similar findings have been reported for the US [22] and for Switzerland [20].

The major limitations of this study concern the limited dataset. First of all the dataset is from only one insurer in one specific Dutch region and the data reflect the behavior of only a small number of GPs with additional training in CAM. This challenges the generalizability of the results. Secondly, the dataset does not cover all the information needed to perform an optimal comparison of cost-effectiveness. Missing information includes costs distinguished by basic and supplementary insurance, out-of-pocket expenses, morbidity, work absence, subjective health, and patient satisfaction.

Consequently, a large number of issues remain for future research. We mention three of them specifically. First, replication studies based on similar data sets are needed to confirm the present results. Secondly, further research is needed to determine to what extent selection on unobservables and causal effects explain the lower costs and lower mortality rates of patients with a GP-CAM. Thirdly, more research is needed with regard to the cost-effectiveness of CAM for specific diagnostic categories. 


\section{References}

\section{[1] http://nccam.nih.gov/health/whatiscam/}

[2] Manheimer, B., Berman, B: Cochrane complementary medicine field. About The Cochrane Collaboration (Fields) 2008, Issue 2. Available at:

http://www.mrw.interscience.wiley.com/cochrane/clabout/articles/CE000052/frame.html

[Accessed 13th May 2009]

[3] Wapf, V., Busato, A: Patients' motives for choosing a physician: comparison between conventional and complementary medicine in Swiss primary care. BMC Complementary and Alternative Medicine 7(1), 41 (2007)

[4] http://www.news.admin.ch/message/index.html?lang=de\&msg-id=37173

[5] Singh, S., Ernst, E.: Trick or treatment. The Undeniable Facts about Alternative Medicine. W. W. Norton \& Company, New York City (2008)

[6] Linde, K., Berner, M.M., Kriston, L.: St. John's wort for major depression. Cochrane Database of Systematic Reviews 2008, Issue 4. Art. No.: CD000448. DOI: 10.1002/14651858.CD000448.pub3

[7] Hopton, A., McPherson, H.: Acupuncture for chronic pain: is acupuncture more than an effective placebo? A systematic review of pooled data from meta-analyses. Pain Practice 10(2), 94-102 (2008)

[8] Van den Berg- Lange, de, C.: The Contribution of Acupuncture and Moxibustion to Healthcare, an Evidence-based Approach. Thesis Erasmus University, Rotterdam (2010)

[9] Servan-Schreiber, D.: Healing without Freud or Prozac: Natural Approaches to Curing Stress, Anxiety and Depression, Rodale Books, Emmaeus (2005) 
[10] www.ivaa.info

[11] www.echamp.be

[12] http://nccam.nih.gov/health/acupuncture/introduction.htm

[13] Herman, P.M., Craig, B.M., Caspi, O.: Is complementary and alternative medicine (CAM) cost-effective? a systematic review. BMC Complementary and Alternative Medicine 5:11 (2005)

[14] Kennedy, D.A., Hart, J., Seely, D.: Cost Effectiveness of Natural Health Products: A Systematic Review of Randomized Clinical Trials. eCAM, 6(3), 297-304 (2009)

[15] Studer, H.P., Busato, A.: Ist ärztliche Komplementärmedizin wirtschaftlich? Schweizerische Ärztezeitung 91, 707-711 (2010)

[16] Nahin, R.L., Barnes, P.M., Stussman, B.J., Bloom, B.: Costs of Complementary and Alternative Medicine (CAM) and Frequency of Visits to CAM Practitioners: United States, 2007. National Health Statistics Reports 18. Available at: http://nccam.nih.gov/news/camstats/costs/nhsrn18.pdf

[17] www.nvaa.nl

[18] www.vhan.nl

[19] www.acupunctuur.com

[20] Esch, B.M., Florica, M., Busato, A., Heusser, P.: Patient satisfaction with primary care: an observational study comparing anthroposofic and conventional care. Health and Quality of Life Outcomes 6:74 (2008) 
[21] Marian, F., Joost, K., Saini, K.D., Ammon, von, K., Thurneysen, A., Busato, A.:

Patient satisfaction and side effects in primary care: An observational study comparing homeopathy and conventional medicine. BMC Complementary and Alternative Medicine 8:52 (2008)

[22] Ness, J., Cirillo, D.J., Weir, D.R., Nisly, N.L., Wallace, R.B.: Use of Complementary Medicine in Older Americans: Results from the Health and Retirement Study. The Gerontologist 45, 516-524 (2005) 


\begin{tabular}{|c|c|c|c|c|}
\hline \multirow[b]{2}{*}{ Costs of health care } & \multirow{2}{*}{$\begin{array}{c}\text { GP } \\
\text { Conventional } \\
\text { GP } \\
\end{array}$} & \multicolumn{3}{|c|}{ GP-CAMs } \\
\hline & & $\begin{array}{c}\text { GP-CAM } \\
\text { anthroposophy }\end{array}$ & $\begin{array}{c}\text { GP-CAM } \\
\text { homeopathy }\end{array}$ & $\begin{array}{c}\text { GP-CAM } \\
\text { acupuncture }\end{array}$ \\
\hline Total & $515^{a}$ & $479 * * *$ & 485 & 480 \\
\hline GP & 32 & $33 * * *$ & $31 * * *$ & 32 \\
\hline Hospital & 266 & $236 * * *$ & 251 & $235 * *$ \\
\hline Pharmaceutical & 209 & $197 *$ & 192 & 206 \\
\hline Paramedic & 9 & $13 * * *$ & $10^{* *}$ & 8* \\
\hline \multicolumn{5}{|l|}{$\begin{array}{l}\text { Incidence of costs of } \\
\text { health care }(0 / 1) \\
\text { (per quarter) }\end{array}$} \\
\hline GP & 1 & 1 & 1 & 1 \\
\hline Hospital & 0.29 & $0.28 * * *$ & $0.26 * * *$ & 0.30 \\
\hline Pharmaceutical & 0.68 & $0.67 * * *$ & $0.62 * * *$ & $0.65 * * *$ \\
\hline Paramedic & 0.04 & $0.06 * * *$ & $0.04 * *$ & $0.04 * *$ \\
\hline $\begin{array}{r}\text { Hosp., Pharma, and/or } \\
\text { Paramedic }\end{array}$ & 0.72 & $0.71^{*}$ & $0.66^{* * *}$ & $0.69 * * *$ \\
\hline Mortality & 0.026 & 0.021 & $0.038 * *$ & 0.025 \\
\hline \multicolumn{5}{|l|}{$\begin{array}{l}\text { Insuree } \\
\text { characteristics }\end{array}$} \\
\hline Female (fraction) & 0.53 & $0.57 * * *$ & $0.56^{* * *}$ & $0.54 * * *$ \\
\hline Birth year (average) & 1969 & $1970 * * *$ & $1965 * * *$ & $1966 * * *$ \\
\hline $\begin{array}{r}\text { Disadvantaged } \\
\text { neighborhood } \\
\text { (fraction) }^{b}\end{array}$ & 0.22 & $0.09 * * *$ & $0.07^{* * *}$ & $0.04 * * *$ \\
\hline $\begin{array}{r}\text { Number of Azivo } \\
\text { insurees }\end{array}$ & 151,952 & 3271 & 1181 & 1470 \\
\hline Number of GPs & 1913 & 26 & 28 & 25 \\
\hline \multicolumn{5}{|c|}{$\begin{array}{l}\text { a Costs of healthcare are in Euros per quarter; } * * *, * *, * \text { indicate a statistically significant difference with } \\
\text { Conventional GP at the } 1,5,10 \text { percent level, respectively. } \\
\text { b Based on a government list of most disadvantaged neighborhoods in the Netherlands ("Vogelaar- } \\
\text { wijken"). These neighborhoods are uniquely identified by their 4-digit postal code. }\end{array}$} \\
\hline
\end{tabular}


Table 2. Costs of health care; by type of GP and insuree age category

\begin{tabular}{|c|c|c|c|c|}
\hline & GPs & \multicolumn{3}{|c|}{ GP-CAMs } \\
\hline $\begin{array}{l}\text { Costs of health care } \\
\text { (euros per quarter) }\end{array}$ & $\begin{array}{c}\text { Conventional } \\
\text { GP }\end{array}$ & $\begin{array}{c}\text { GP-CAM } \\
\text { anthroposophy }\end{array}$ & $\begin{array}{c}\text { GP-CAM } \\
\text { homeopathy }\end{array}$ & $\begin{array}{c}\text { GP-CAM } \\
\text { acupuncture }\end{array}$ \\
\hline \multicolumn{5}{|l|}{ Age 0-24 } \\
\hline Total & $215^{a}$ & 190 & 275 & 191 \\
\hline GP & 26 & 26 & $24 * * *$ & 25 \\
\hline Hospital & 103 & $85^{*}$ & $153^{* *}$ & 96 \\
\hline Pharmaceutical & 77 & 69 & 88 & 62 \\
\hline Paramedic & 8 & $11 * * *$ & 10 & 8 \\
\hline \multicolumn{5}{|l|}{ Age 25-49 } \\
\hline Total & 372 & $418 * * *$ & $286 * *$ & $296 * * *$ \\
\hline GP & 28 & $31 * * *$ & $25 * * *$ & $26 * * *$ \\
\hline Hospital & 186 & 201 & 156 & $146 * *$ \\
\hline Pharmaceutical & 155 & $180^{* * *}$ & $103^{* * *}$ & $122 * *$ \\
\hline Paramedic & 4 & $7 * * *$ & 3 & $1 * * *$ \\
\hline \multicolumn{5}{|l|}{ Age $50-74$} \\
\hline Total & 824 & $752 * *$ & 614*** & $687 * * *$ \\
\hline GP & 37 & $39 * * *$ & $35 * * *$ & $35 * * *$ \\
\hline Hospital & 432 & $382 * *$ & $270 * * *$ & $324 * * *$ \\
\hline Pharmaceutical & 342 & $311 * *$ & $294 *$ & 317 \\
\hline Paramedic & 12 & $19 * * *$ & $14^{*}$ & 11 \\
\hline \multicolumn{5}{|l|}{ Age 75+ } \\
\hline Total & 1337 & $1088 * *$ & 1309 & 1139* \\
\hline $\mathrm{GP}$ & 57 & 57 & 59 & 56 \\
\hline Hospital & 727 & $576 * *$ & 820 & 595 \\
\hline Pharmaceutical & 527 & $426 * *$ & $403 *$ & 466 \\
\hline Paramedic & 27 & 30 & 27 & 21 \\
\hline
\end{tabular}

${ }^{a}$ Costs of healthcare are in Euros per quarter

***, **, * indicate a statistically significant difference with Conventional GP at the 1, 5, 10 percent level, respectively. 


\section{Table 3. Effects of complementary care on costs per insuree age category}

\begin{tabular}{|c|c|c|c|c|c|c|}
\hline & \multicolumn{3}{|c|}{ Linear } & \multicolumn{3}{|c|}{ Loglinear } \\
\hline & $\begin{array}{l}\text { dummy } \\
\text { for GP- } \\
\text { CAM } \\
\text { anthro- } \\
\text { posophy }\end{array}$ & $\begin{array}{l}\text { dummy } \\
\text { for GP- } \\
\text { CAM } \\
\text { homeo- } \\
\text { pathy }\end{array}$ & $\begin{array}{l}\text { dummy } \\
\text { for GP- } \\
\text { CAM } \\
\text { acupunc- } \\
\text { ture }\end{array}$ & $\begin{array}{c}\text { dummy } \\
\text { for GP- } \\
\text { CAM } \\
\text { anthro- } \\
\text { posophy }\end{array}$ & $\begin{array}{l}\text { dummy } \\
\text { for GP- } \\
\text { CAM } \\
\text { homeo- } \\
\text { pathy }\end{array}$ & $\begin{array}{l}\text { dummy } \\
\text { for GP - } \\
\text { CAM } \\
\text { acupunc- } \\
\text { ture }\end{array}$ \\
\hline \multicolumn{7}{|l|}{ Age 0-24 } \\
\hline Total & $6^{a}$ & 100 & -32 & 0.016 & $-0.138 * *$ & -0.052 \\
\hline GP & 1 & $-2 *$ & 1 & 0.015 & $-0.043 *$ & 0.019 \\
\hline Hospital & 3 & 76 & -5 & 0.064 & $-0.153^{*}$ & -0.034 \\
\hline Pharmaceutical & 1 & 25 & -27 & $-0.078^{*}$ & $-0.250 * * *$ & -0.108 \\
\hline Paramedic & 2 & 0 & -1 & 0.048 & -0.006 & -0.008 \\
\hline \multicolumn{7}{|l|}{ Age 25-49 } \\
\hline Total & 14 & -50 & $-66^{*}$ & 0.022 & $-0.160 * *$ & $-0.106 * *$ \\
\hline GP & $2 * * *$ & $-3 * * *$ & 0 & $0.030 * *$ & $-0.045 * *$ & -0.004 \\
\hline Hospital & 3 & 4 & $-47 * *$ & 0.008 & $-0.161 * *$ & $-0.135 * *$ \\
\hline Pharmaceutical & 8 & $-51 * *$ & -17 & -0.035 & $-0.365 * * *$ & $-0.136 *$ \\
\hline Paramedic & 1 & -1 & $-2 * * *$ & 0.032 & -0.029 & $-0.060 * * *$ \\
\hline \multicolumn{7}{|l|}{ Age 50-74 } \\
\hline Total & 63 & -48 & -2 & -0.030 & $-0.153^{* *}$ & -0.084 \\
\hline GP & $4 * * *$ & 0 & 0 & $0.040^{*}$ & -0.001 & 0.017 \\
\hline Hospital & 60 & -121 & -64 & 0.032 & -0.145 & -0.073 \\
\hline Pharmaceutical & -7 & 69 & 61 & $-0.204 * * *$ & $-0.352 * * *$ & -0.162 \\
\hline Paramedic & 6* & 4 & 1 & 0.080 & 0.016 & -0.009 \\
\hline \multicolumn{7}{|l|}{ Age 75+ } \\
\hline Total & $-405 * *$ & 81 & 214 & -0.130 & 0.077 & 0.184 \\
\hline GP & -2 & 6 & 7 & -0.030 & 0.058 & 0.111 \\
\hline Hospital & $-263 * *$ & 52 & 87 & -0.029 & 0.069 & 0.171 \\
\hline Pharmaceutical & $-125 *$ & 31 & 127 & -0.169 & 0.048 & 0.196 \\
\hline Paramedic & -15 & -8 & -7 & -0.106 & -0.085 & 0.034 \\
\hline \multicolumn{7}{|c|}{$\begin{array}{l}{ }^{a} \text { Costs of healthcare are in Euros per quarter. Each row is based on two regressions with either costs (left } \\
\text { panel) or the natural logarithm of costs (right panel) as the dependent variable. Explanatory variables are: } \\
\text { gender, age (linear, within each age category), dummies for each quarter, dummies for anthroposophy, } \\
\text { homeopathy, and acupuncture; the table reports the coefficients on the latter dummies. All regressions control } \\
\text { for 6-digit insuree postcode fixed effects; standard errors clustered at the insuree level. } \\
* * *, * *, * \text { indicate a statistically significant difference with Conventional GP at the } 1,5,10 \text { percent level, } \\
\text { respectively. }\end{array}$} \\
\hline
\end{tabular}




\begin{tabular}{|c|c|c|c|c|}
\hline & $\begin{array}{l}\text { dummy for GP- } \\
\text { CAM } \\
\text { anthroposophy }\end{array}$ & $\begin{array}{c}\text { dummy for GP- } \\
\text { CAM } \\
\text { homeopathy }\end{array}$ & $\begin{array}{c}\text { dummy for GP- } \\
\text { CAM } \\
\text { acupuncture }\end{array}$ & Combined \\
\hline Logit with fixed effects & 0.031 & -0.198 & $-0.333 *$ & -0.128 \\
\hline LPM with fixed effects & $-0.005^{*}$ & -0.004 & $-0.009 * *$ & $-0.006 * * *$ \\
\hline \multicolumn{5}{|l|}{ Women } \\
\hline Logit with fixed effects & 0.034 & 0.010 & -0.203 & -0.031 \\
\hline LPM with fixed effects & $-0.007^{*}$ & 0.004 & -0.008 & $-0.005^{*}$ \\
\hline \multicolumn{5}{|l|}{ Men } \\
\hline Logit with fixed effects & 0.020 & $-0.627^{*}$ & -0.493 & $-0.291^{*}$ \\
\hline LPM with fixed effects & -0.003 & -0.014 & $-0.013 * *$ & $-0.008 * *$ \\
\hline \multicolumn{5}{|c|}{$\begin{array}{l}\text { Dependent variable: death in } 2006,2007,2008 \text {, or } 2009 \text {. } \\
\text { The table is based on models with the following explanatory variables: gender, age, dummies for anthroposophy } \\
\text { homeopathy, and acupuncture (dummy for complementary in the last column); the table reports the coefficients } \\
\text { on the latter dummies. } \\
\text { LPM regression controls for 4-digit insuree postcode fixed effects. } \\
* * *, * *, * \text { indicate a statistical significance at the } 1,5,10 \text { percent level, respectively. }\end{array}$} \\
\hline
\end{tabular}

